\title{
Assistência estudantil brasileira e a experiência da Uerj: entre a inovação e o atraso na atenção ao estudante
}

Brazilian student aid and the Uerj experience: between innovation and backwardness in student assistance

\author{
Simone Eliza do Carmo Lessa
}

\begin{abstract}
Resumo - Apresentamos a política de assistência estudantil brasileira em sua trajetória história e em conexão com o trabalho dos assistentes sociais. Apontamos, ainda, a experiência de atenção ao estudante construída na Uerj, refletindo acerca das potencialidades não exploradas contidas nesta instituição. Por fim, destacamos a importância da constituição de uma efetiva assistência estudantil na Uerj.

Palavras-chave: educação; assistência estudantil; Serviço Social; Uerj.
\end{abstract}

\begin{abstract}
In this article, we present the policy and historical trajectory of Brazilian student aid, in connection with the activity of social workers. We analyze as well the experience of attention to students at Rio de Janeiro State University (UERJ), reflecting upon its unexplored potential. Finally, we present the importance of effective affirmative action at UERJ.

Keywords: education; student aid; Social Work; Uerj.
\end{abstract}

\section{Introdução}

Na presente reflexão resgatamos elementos da história das formas iniciais de apoio à permanência do estudante praticadas na Universidade do Estado do Rio de Janeiro (Uerj), segundo registros do nosso próprio trabaIho como assistente social nesta instituição (portanto, a partir de nossa memória), bem como por meio de pesquisa a documentos institucionais que registram esse processo.

Sobre isso, cabe ressaltar que, segundo Le Goff (1990), a memória está nos próprios alicerces da história, embora só recentemente tenha se

\footnotetext{
* Assistente Social. Doutora em Serviço Social (UFRJ) e Professora do Departamento de Políticas Sociais da Faculdade de Serviço Social da Universidade do Estado do Rio de Janeiro (DPS/FSS/UERJ). Correspondência: Boulevard 28 de setembro, 292/apt. 401 - Vila Isabel - Rio de Janeiro. CEP 20551 031. Email: <elizasimone@gmail $. \mathrm{com}>$.
} 
tornado objeto da historiografia. A memória trata do vivido, do experimentado em uma experiência pessoal e coletiva. Neste caso, traremos a experiência de profissionais de Serviço Social em uma universidade pública, implementando políticas voltadas à permanência estudantil, em seus primeiros e inacabados formatos.

Partimos da premissa da relevância e da urgência dessa política em um contexto de mais de uma década de exitosa experiência afirmativa das cotas e do consequente crescimento da demanda dos estudantes por permanência de qualidade. Nesse sentido, no presente artigo apresentamos a defesa da assistência estudantil como política universitária associada à já existente e organizada política de cotas. Ao mesmo tempo, fazemos a defesa da construção de uma universidade com perfil popular, sendo um espaço onde a classe trabalhadora e seus filhos se sintam recebidos e ouvidos como protagonistas na construção de saberes e na materialização de uma educação pública de qualidade, crítica, humanista e laica. Essa é, ainda, uma reflexão militante que lança mão de uma análise histórica sobre a política de educação, especialmente no Ensino Superior, aqui tardiamente implementado, e sobre a assistência estudantil, abordando especialmente a construção dessa experiência na Uerj, na intenção de fazer a defesa da mesma.

Uma vez postas nossas intenções de escrita, apresentamos a forma como está organizado o texto: faremos um breve resgate histórico sobre o trabalho do assistente social na educação, visando alcançar sua experiência como profissional de destaque na viabilização da política de assistência estudantil. A seguir, apresentaremos a constituição da política de assistência estudantil no Brasil contemporâneo, passando a apresentar, por fim, a experiência uerjiana.

\section{Serviço Social na Educação}

O Serviço Social é uma profissão que foi organizada para atuar nas expressões da questão social quando essas se mostravam mais complexas e cotidianas nos marcos do capitalismo monopolista e da emersão do operariado como sujeito político que clamava por melhores condições de trabalho e de vida. Estamos falando dos anos de 1930, no Brasil, quando protoformas de políticas sociais estão sendo organizadas por um modelo de Estado que se pretende harmonizador de conflitos, conciliador de inconciliáveis interesses do capital e dos trabalhadores.

Nossa presença como profissão está, portanto, associada ao desenvolvimento das políticas sociais no Brasil, especialmente no campo da atenção à infância, ao adolescente e à família trabalhadora, mas não apenas. A política de educação e a escola, em particular, serão espaços de absorção dos assistentes sociais e de legitimação de sua existência. Dialogando com Witiuk (2004), identificamos que nos anos de 1940 os assistentes sociais 


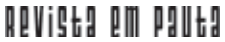

\} ASSISTENNCIA ESTUDANTIL BRASILEIRA - LESSA, S. E. C. \}

DOI $10.12957 /$ REP.2017.30381

foram chamados a uma intervenção acrítica sobre as expressões da questão social, dentre essas, aquelas manifestadas nos espaços educacionais formais. Na escola o Serviço Social será requisitado para o exercício de atribuições que harmonizam as relações no processo de vigilância da moral e da sociabilidade das famílias empobrecidas (WITIUK, 2004, pag. 24), cujos filhos, futura geração de trabalhadores urbanos, começam timidamente a ingressar ali.

A escola pública vai se configurando como espaço para estimular posturas adequadas ao padrão burguês ascendente, de clara inspiração higienista. A instituição escolar estava submetida à nova ordem urbana, assalariada, fabril e desigual, materializando uma perspectiva moralizadora de condutas que Passetti (2000), definirá como ações que levam a escola contra a família (certamente, as famílias pobres). Novamente dialogando com Witiuk (2004) verificamos que o I Congresso Brasileiro de Serviço Social, ocorrido em 1947, indica a importância da efetivação do chamado Serviço Social Escolar (o que revela a importância do tema frente à categoria). Este, então, é definido como uma atividade técnica e supletiva às ações da formação, objetivando o ajustamento dos indivíduos.

Vale lembrar que a inserção do assistente social no campo educacional ficará mais evidente nos anos de 1950, com a expansão do aparato público brasileiro. Começam a fazer parte do cotidiano do trabalho do assistente social, a participação em programas de alfabetização de adultos junto ao Desenvolvimento de Comunidade (AMMANN, 1987) e a formação profissional junto aos trabalhadores e seus filhos no Sistema "S" e nas creches, denominadas "parques infantis" (então vinculadas à assistência social, notadamente à Legião Brasileira de Assistência (LBA), além das escolas. Importante assinalar que nas creches da LBA em muito cresceu a legitimidade da atuação do assistente social na educação.

Na chamada educação popular de inspiração freiriana' ${ }^{1}$, também verificamos registros da presença de assistente sociais (NETTO, 1991)². Além dessas experiências, os assistentes sociais que atuavam com aqueles então denominados "menores", por vezes, precisavam realizar articulações entre escola, família e aprendizado para o trabalho - lembrando que historicamente, a educação profissional é o campo formativo ao qual acorrem os filhos da classe trabalhadora (MANFREDI, 2003). Dialogando com Maria Isolina Pinheiro (1985) em obra que discute a chamada infância desvalida, verificamos que a autora discorre sobre a importância da atenção às crianças na escola, indicando o assistente social como um significativo agente no aclaramento sobre a vida do estudante em sua realidade social.

\footnotetext{
1 Baseadas no pensamento do educador e filósofo Paulo Freire, tais como o Movimento de Educação Popular e o De Pé no Chão Também se Aprende a Ler.

${ }^{2}$ Netto (1991) ressalta que a apropriação do pensamento de Paulo Freire pelo Serviço Social acontece sob a perspectiva do ecletismo, em especial frente aos conceitos de oprimido e de conscientização trabalhados pelo educador. Sua apreensão no Método BH fica evidente, segundo o autor. Ver mais em Ditadura e Serviço Social (NETTO, 1991).
} 
A Ditadura Militar Empresarial iniciada em 1964 nos deixa como legado a degradação da educação pública em todos os níveis (NETTO, 1991). A escola pública e sua qualidade serão atacadas, seu papel social aviltado, o salário docente achatado e o papel social do mesmo minimizado. As reformas educacionais da Ditadura (na universidade em 1968 e na educação profissional em 1971) estavam submetidas a interesses mercantis e privatistas, fragilizando a formação em curso. A universidade será reprimida e cindida em créditos, a escola profissionalizante não profissionalizará efetivamente e tampouco oferecerá educação propedêutica. Seu financiamento será atacado, inexistindo mínimo constitucional a ser aplicado nessa política (SAVIANI, 2008). O ocaso da autocracia reacenderá os debates e as lutas pelo direito à educação, revelando dados terríveis sobre o analfabetismo e a deterioração da escola pública: no ano de 2000 havia mais analfabetos, em números absolutos, do que em 1960 (INEP, 2013).

No processo de redemocratização da sociedade brasileira, frente à ampliação do acesso à educação nas décadas de 1980 e 1990, cresce a atuação de profissionais de Serviço Social nas políticas educacionais (ALMEIDA, 2003). Trata-se da evidência de expressões da questão social naquele espaço. Como exemplo da presença de assistentes sociais na escola fluminense nesse período, citamos os Centros Integrados de Educação Pública, os $\mathrm{Cieps}^{3}$ e, nacionalmente, lembramos de iniciativas como as do Bolsa-Escola, desenvolvido em algumas prefeituras brasileiras, em especial no Sul e no Sudeste.

Hoje podemos afirmar que na área de Educação o assistente social tem atuado no âmbito da garantia de acesso, de permanência e na gestão democrática (ALMEIDA, 2003). Acrescentamos com base na nossa experiência que esse profissional também atua na aproximação das redes de serviços e das equipes multidisciplinares, no desenvolvimento de temas transversais à formação, na atenção aos deficientes e suas famílias. Neste sentido, atuar sobre as expressões da questão social e fazer ver como estas impactam na aprendizagem e na permanência, são realidades do trabalho do Serviço Social.

Neste sentido, o trabalho do assistente social na Educação é desafiado, permanentemente, diante da questão social muito evidenciada nos espaços formativos, em especial no Ensino Fundamental da escola pública, em um país que tardiamente inicia processo de massificação do acesso a essa fase do ensino - após a Constituição de 1988 (BRASIL, 1988) - sem que condições dignas de vida de crianças, adolescentes e suas famílias tenham sido alcançadas.

\footnotetext{
${ }^{3}$ Os Cieps (Centos Integrados de Educação Pública) se constituíram em importante política do governo Brizola no Estado do Rio de Janeiro. Trata-se de experiência de escola integral, elogiada pela infraestrutura material e criticada por não chegar às crianças que viviam em situações econômicas complexas que lhes impediam a frequência à escola e aquelas que eram trabalhadoras.
} 


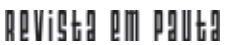

\} ASSISTENNCIA ESTUDANTIL BRASILEIRA - LESSA, S. E. C. \}

DOI 10.12957/REP.2017.30381

Nesse sentido, mais acesso à escolarização não tem significado mais qualidade na educação pública. Ao contrário: tal ampliação tem acontecido "para menos" (ALGEBAILE, 2009), ou seja, sem que a infraestrutura da qualidade dos equipamentos, salários e condições do trabalho docente tenham sido alterados positivamente. Além disso, o processo de formar não se restringe ao interior da escola. Por isso, não basta uma educação de meIhor qualidade em um contexto de precariedades - como os espaços onde vivem as populações mais empobrecidas. Em outras palavras, políticas educacionais, desarticuladas de outras políticas sociais, têm menor efetividade.

Tendo isso em conta, é importante registrar que não compartilhamos de concepções que culpam indivíduos por supostos "fracassos" na vida escolar. Da mesma forma, não queremos responsabilizar os professores. Ao contrário disso, acreditamos que a precarização da vida, das condições de sobrevivência, o aviltamento dos direitos sociais e políticos contribuem para o não exercício da condição de sujeito de direitos, aquele que participa da vida em sociedade em condições que dignificam sua existência. Em outras palavras, a falta de acesso aos processos civilizatórios pode comprometer a vida, inclusive os processos de aprendizagem.

O trabalho do assistente social se inscreve nesta realidade complexa de mais acesso e menor qualidade da educação. Também está inserido em uma totalidade maior, contraditória, tensionada por interesses do capital e dos trabalhadores, que se expressam em projetos educacionais distintos. Nesse marco de interesses antagônicos, o trabalho do assistente social tem se desenvolvido e crescido, experimentando avanços e potencialidades, dificuldades e limitações. Prefeituras tais como as do Rio de Janeiro, São Caetano, Belo Horizonte, por exemplo, inserem o assistente social em ações diversas da rede escolar de Ensino Fundamental. Na rede federal o assistente social tem atuado no Ensino Básico, Superior, na Educação Profissional e na Educação de Jovens e Adultos (EJA), com destaque para ações na política de assistência estudantil. Nessa política o exercício profissional vive momento de expansão, de estudo de suas potencialidades e limitações.

\section{Assistência estudantil brasileira: breve histórico}

As primeiras experiências de assistência estudantil estiveram vinculadas ao Ensino Superior ${ }^{4}$. A expansão desse nível educacional data dos anos de 1950, em momento de aprofundamento da industrialização, embora sua origem esteja relacionada à chegada da Família Real ao Brasil, em 1808, quando a realeza e seus nobres para cá se mudam, trazendo na bagagem o

\footnotetext{
${ }^{4}$ Na primeina década do século XXI verificamos sua expansão no Ensino Básico, através de legislações estaduais (Lei 6434/2013/RJ). Além disso, sua ampliação no nível Médio no âmbito federal, através da Educação Profissional também é visível.
} 
modelo europeu de universidade. Como elementos históricos desse processo, queremos destacar a implantação, ainda no século XIX, das primeiras instituições formativas de nível superior, com destaque para as áreas de Medicina e Direito. Tais instituições se fixam na Bahia, Recife, São Paulo e Minas Gerais, localidades de destaque frente à economia agroexportadora.

Mais de um século depois da fundação dessas primeiras instituições, ou seja, tardiamente, inclusive em relação à América Latina, ocorrerá sua expansão, por meio de um padrão de formação submetido ao capitalismo periférico, no qual a predominância da geração de postos simples de trabalho para a maioria da massa trabalhadora, não exige a ampliação do acesso ao conhecimento complexo (FRIGOTTO, 1993). Sendo assim, a universidade será para poucos. Mesmo assim a educação superior será uma demanda crescente do movimento de trabalhadores e das camadas médias urbanas e no final dos anos de 1950, se constituirá em importante bandeira de luta dos movimentos por reformas de base (FRANCO, 2008).

De fato, a efetivação da expansão universitária ocorrerá nos anos de 1970, estando relacionada à Ditadura militar que a executa por meio de instituições privadas nos grandes centros urbanos. Naquele momento havia a necessidade de formar mão-de-obra especializada para um Estado que crescia em atividades e instituições, bem como para um mercado de trabalho urbano em expansão. Tal ampliação intencionava, ainda, minimizar as demandas das camadas médias urbanas por vagas universitárias, em um contexto de repressão das oposições (ROMANELLI, 2001). Como exemplo da expansão, ressaltamos que em 1960 existiam 200 mil matrículas nessa modalidade e que em 1980 esse número chega a 1,4 milhões, localizados principalmente na rede privada (SAMPAIO, 2011).

Nas últimas décadas, resumidamente, podemos afirmar que a Educação Superior terminou por se constituir em um modelo em que predominam as instituições privadas, de pequeno porte, portanto, não universitárias, protegidas legalmente da necessidade de realizar pesquisa e extensão. Acrescente-se que tais instituições são marcadas cada vez mais por uma recente e inadequada expansão da modalidade de educação a distância - EAD - (FRANCO, 2008). Além disso, podemos registar a ocorrência de um aligeiramento da formação que não poupa a Educação Superior (LESSA, 2011).

Posta essa breve apresentação da Educação Superior no Brasil, podemos avaliar que sua construção, em uma realidade de país periférico, atendeu muito mais às necessidades das elites econômicas, da acumulação e de eixos produtivos específicos, do que aos anseios da população trabaIhadora. Nossa condição de país dependente trará reflexos na constituição na educação básica e na formação superior de modo particular, que se mostrará tardia, subordinada cientificamente, fragmentada e elitizada (FERNANDES, 1989). Esse quadro de subordinação permanece em curso, ainda que existam resistência e produção científica de excelente qualidade nas 


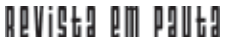

\} ASSISTENNCIA ESTUDANTIL BRASILEIRA - LESSA, S. E. C. \}

DOI 10.12957/REP.2017.30381

universidades públicas, mas a lógica que alicerça a política educacional é a que perpetua o histórico lugar de periferia. Além disso, nas palavras de Boschetti (2016, p. 17) "o ensino superior expressa as tendências destrutivas e mercantilizantes agudizadas pela contraofensiva do capital em tempos de crise".

Olhando para nosso objeto de análise - a assistência estudantil e tratando de sua história, Andres (2011) destaca como primeiras expressões dessa experiência, as ações para alimentação e moradia universitárias organizadas pontualmente em instituições federais de maior porte, com destaque para a região Nordeste e o interior de Minas Gerais. Importante evidenciar a experiência da Fump (assistência estudantil da UFMG), que oferece bolsas, material didático, alojamento e alimentação há oito décadas, por meio de recursos gerados pelo pagamento de matrículas e doações. Este modelo de assistência estudantil mineiro desenvolveu-se a partir da criação da UMG (Universidade de Minas Gerais), fundada em 1927, que então cobrava matrículas. Em 1929 é criada a AUM (Associação Universitária Mineira) que visava prestar assistência jurídica, médica e odontológica a estudantes pobres. A atual FUMP foi criada em 1973 quando a UMG já havia se tornado UFMG e federalizada (UFMG, FUMP, 2016).

No entanto, a partir do Programa Nacional de Assistência Estudantil (PNAES) os recursos da Fump passaram a vir do Governo Federal, embora campanhas para arrecadação de fundos continuem acontecendo. Cumpre destacar que discordamos totalmente desse modelo híbrido que envolve recursos públicos e doações, entendendo que a educação é dever do Estado e por este deve ser financiada.

Em se tratando da profissão ressaltamos que ao longo dos anos de 1970, em um momento de ampliação da Educação Superior, através dos DAEs (Departamentos de Assistência Estudantil), as experiências de assistência estudantil começam a se expandir nas universidades federais. Cabe salientar que muitos assistentes sociais foram incorporados à educação federal nos anos de 1980 e início dos anos de 1990, em função de programas de assistência estudantil, conforme nossa vivência profissional.

Na década de 1980, em franco processo de redemocratização da sociedade brasileira, Pró-Reitores de Assuntos Comunitários organizam-se em prol da estruturação de políticas de promoção estudantil (REVISTA FONAPRACE, 2012). Em 1985 foi realizado, em Santa Catarina, o I Encontro de Pró-Reitores de Assistência à Comunidade Universitária, congregando 27 universidades federais, visando pensar estratégias para provimento de condições mínimas à permanência dos estudantes nessas instituições. Os estados do Norte e Nordeste, por meio de suas universidades, serão grandes defensores e protagonistas deste processo.

O encontro de 1985 será seguido de outros que ressaltarão a importância do apoio ao estudante universitário, buscando traçar diretrizes para tanto. Naquele período destacava-se a urgência de prover e melhorar 
Restaurantes Universitários. O Fórum Nacional de Pró-Reitores para Assuntos Comunitários e Estudantis (FONAPRACE) será criado em 1987, com a meta de discutir, elaborar e propor ao MEC a política de promoção e apoio ao estudante na rede federal superior. $O$ documento de criação do fórum é organizado em um contexto de retomada da democracia e traz críticas ao MEC avaliando que este buscava se desobrigar de suas responsabilidades frente à assistência estudantil (REVISTA FONAPRACE, 2012).

Como resultado desse processo de mobilização e democracia, quatro anos depois da criação do Fórum, um importante marco documental é produzido - o Plano Nacional de Assistência Estudantil para o Ensino Superior das Instituições Federais Públicas. Este foi elaborado pelo FONAPRACE e encaminhado à Associação Nacional de Dirigentes das Instituições Federais de Ensino Superior (Andifes) em 2001, durante governo de FHC. Trata-se de importante normativa que estrutura a ideia da assistência estudantil no contexto democrático, produzida dentro dos embates por educação pública em uma realidade de retrocessos neoliberais, quando se falava, inclusive, na cobrança de mensalidades nas universidades federais. Este documento defendia a assistência estudantil como política para redução de desigualdades sociais refletidas na formação, a partir do favorecimento da permanência e do combate à evasão (REVISTA FONAPRACE, 2012).

As bases legais que fundamentam a assistência estudantil na referida documentação são a Constituição Federal de 1988, o Plano Nacional de Educação (Lei 10.172, PNE/2001) e a LDBN (Lei 9394/1996). Nas três legislações destaca-se a educação como dever do Estado e a importância do provimento de igualdade de condições de acesso e permanência. Por fim, o documento sinaliza que cabe às universidades públicas assumirem a assistência estudantil como direito e espaço prático de cidadania.

Entendemos que o Plano Nacional de Assistência Estudantil para o Ensino Superior das Instituições Federais públicas reflete um momento de luta pela democracia e de reconhecimento de que a universidade pública deve ser ampliada. Esse documento contém a marca da mobilização de gestores e técnicos em torno da assistência estudantil. No entanto, em sua elaboração, faltou participação mais efetiva dos movimentos de estudantes, que não integraram sua construção. A decorrente falta de êxito pode ser atribuída à duríssima conduta neoliberal do Governo $\mathrm{FHC}$, à política de precarização e desqualificação da educação pública e em função da pouca visibilidade dada ao tema naquele momento.

Chegando aos perfis de estudantes traçados pelo FONAPRACE (REVISTA FONAPRACE 2012), lembramos que o primeiro destes foi elaborado com base em pesquisa socioeconômica e cultural efetivada na rede federal nos anos de 1993/1994. Seu resultado revela que as dificuldades econômicas e a desigualdade que marcam a sociedade brasileira estavam também presentes no interior das universidades, impactando na permanência dos estudantes e em suas condições para aprendizado. Nesse estudo inicial 


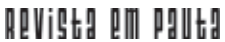

\} ASSISTENNCIA ESTUDANTIL BRASILEIRA - LESSA, S. E. C. \}

DOI $10.12957 /$ REP.2017.30381

foram analisadas $84,6 \%$ das instituições nacionais, depreendendo-se que $42,2 \%$ dos estudantes pertenciam às camadas mais pobres da população (denominadas ali de classes C, D e E). Esses alunos estavam concentrados em cursos menos elitizados, mas sua presença era inegável.

Pesquisas de mesmo tipo foram realizadas pelo fórum em 2003/ 2004 revelando que em média nacional de 43\% dos estudantes da Educação Superior têm origem nos segmentos mais empobrecidos da população (confirmando os dados colhidos no início dos anos 1990). Em nova pesquisa realizada em 2010 ficou revelado o crescimento do acesso dos negros, denotando o êxito das políticas afirmativas iniciadas nos primeiros anos do século XXI. A pesquisa indica, ainda, que os estudantes que demandam esse tipo de política têm o seguinte perfil: em sua maioria são mulheres jovens, solteiras, com média de idade de 23 anos, que utilizam o transporte público e acessam o ensino em busca de melhores condições de vida e de ingresso ao mercado de trabalho. A pesquisa revela, ainda, que $35 \%$ dos entrevistados migraram para regiões distantes, com o intuito de estudar. Não por acaso, dentre as principais demandas desses alunos, estão o alojamento, a alimentação (através do restaurante universitário, encarado pelos estudantes como espaço de convivência e de troca, segundo a mesma pesquisa), além da bolsa.

Ainda destacando o perfil dos estudantes que demandam a assistência estudantil, dessa vez ressaltando a questão de gênero, outra pesquisa agora realizada pela ANDIFES, divulga dados referentes a 2014.

i) as graduandas provêm de famílias com renda familiar per capita média $(R \$ 835,10)$ inferior a dos indivíduos do sexo masculino $(R \$ 1.007,19)$; ii) os homens, de modo geral, possuem maior domínio no uso dos computadores; iii) homens são maioria entre estudantes que se envolvem com algum tipo de movimento (artístico, cultural, político etc); iv) homens são a maioria dos beneficiários dos programas de mobilidade internacional. Assim, a despeito da maior inserção das mulheres no ensino superior, ainda restam inúmeras desigualdades para serem enfrentadas em prol de relações de gênero mais igualitárias (ANDIFES, 2016 n. p.).

Destacamos, ainda, o aspecto da renda no mesmo estudo: $66,19 \%$ dos discentes das IFES vivem com renda per capita média familiar de até 1,5 salário mínimo (sendo que 31,97\% vivem com até 0,5 salário mínimo, e 21,96\% vivem com renda entre 0,5 e 1 salário mínimo. (ANDIFES, 2016 n.p.).

Neste momento, em 2016, nova pesquisa de perfil está sendo realizada na Universidade de São Carlos, numa iniciativa que integra o Observatório Fonaprace ${ }^{5}$. Ressaltamos por fim, sobre as pesquisas, que o diagnóstico feito no início dos anos de 1990 permanece atual: a demanda

${ }^{5}$ Criado a partir de parceria do FONAPRACE com a ANDIFES. 


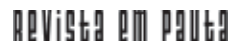

\} ASSISTÊNCIA ESTUDANTIL BRASILEIRA - LESSA, S. E. C. \}

DOI 10.12957/REP.2017.30381

por assistência estudantil é presente, crescente e justificada, Temos nas universidades brasileiras significativo grupo de jovens empobrecidos, de modo que podemos afirmar que políticas que visam à permanência e o aprendizado podem ser chamadas de políticas de proteção à juventude. Neste sentido, garantia de acesso e permanência na educação pública, inclusive ao Nível Superior, devem ser valorizadas como proteção social e política para a juventude pobre.

Retomando o debate histórico sobre a estruturação da Política de Assistência Estudantil lembramos que, buscando normatizá-la em 2007, durante o segundo Governo Lula da Silva, gestores ligados ao Fonaprace atualizam o documento que versa sobre a assistência estudantil na rede federal, acima comentado (FONAPRACE, 2012). Tal documento fora encaminhado sem êxito ao Governo FHC, sendo retomado seis anos depois, como fundamento da discussão sobre a assistência estudantil junto ao MEC.

Foi somente em 2007, ou seja, tardiamente, se lembrarmos que o documento inicial desta reflexão data de 2001, o Plano Nacional de Assistência Estudantil (PNAES) recebeu aprovação como Portaria Normativa 39. Ainda que sua materialização seja limitada, inclusive por constituir-se como portaria governamental, o que lhe confere caráter transitório e frágil, trata-se de um marco legal importante no campo da assistência estudantil, pois, se delineia seu escopo de ações. A portaria será transformada em Decreto (7234/2010), permanecendo com limites em termos de formato legal.

Vale mencionar que o documento de 2010 é um pouco mais extenso, pois apresenta os objetivos da PNAES em seu segundo artigo, a saber: democratizar as condições de permanência, minimizar efeitos da desigualdade social e regional, reduzir as taxas de retenção, evasão e contribuir para a promoção da inclusão. Neste sentido, há maior explicitação de ideias relativas à permanência no documento de 2010. Contudo, esse ainda não se constitui em uma política de Estado de efetiva existência como tal, pois permanece como um plano, podendo ser extinto, ao sabor das vontades dos governos.

O contexto da efetivação do decreto de 2010 é de mobilização em momento um eleitoral em que o PT busca reeleição, desta vez tendo como candidata a então Ministra Dilma Roussef. Abrimos um parêntesis para comentar que Rousseff sofreu processo de impeachment em 2016. Em seu lugar assumiu seu vice, Michel Temer, figura importante do PMDB com quem o PT construiu sua contraditória e nefasta base de governabilidade. Os impactos desta deposição, que visa fazer contrarreformas cada vez mais identificadas com os interesses do capital privado, que a ex-presidente não conseguia mais viabilizar, estão se desenrolando, mas seus efeitos nocivos no financiamento das políticas sociais são evidentes. Neste sentido, foi apro-vada a PEC do teto dos gastos públicos que congela investimentos nos próximos 20 anos

Por fim, entendemos que a demora entre a base documental elaborada pelo Fonaprace em 2001, a portaria de 2007 e, finalmente, o decreto 


\section{ReVistg QII paltg}

\} ASSISTENNCIA ESTUDANTIL BRASILEIRA - LESSA, S. E. C. \}

DOI $10.12957 /$ REP.2017.30381

de 2010, revela tensões entre os interesses em torno do acesso e permanência na educação pública em contraste com os interesses mercantis na Educação Superior.

Diante desses interesses opostos queremos salientar que a realidade dos governos do PT (de Lula ao primeiro Governo Dilma) é bastante contraditória. De um lado, há um Ensino Superior mercantilizado para estudantes consumidores empobrecidos - que ingressam nas instituições privadas de qualidade questionável, por meio de programas como o Programa Universidade Para Todos (ProUni) e do (Fundo de Financiamento Estudantil (FIES). Apesar disso, de outro lado, há também estudantes empobrecidos, mas que conseguem acessar a educação pública - por razões que merecem mais análises, mas que não são objeto desta reflexão - por meio de instituições que foram ampliadas sem condições adequadas para tanto, pela via do Programa de Reestruturação e Expansão das Universidades Federais (ReUni). Essas são situações distintas, mas têm em comum a expansão precarizada da Educação Superior. Sim, teremos mais alunos matriculados e concluindo esse nível educacional com uma formação fragilizada e superficial. Os desdobramentos desse fato nos desafiam.

Novamente, nos defrontamos com uma ampliação educacional para menos (ALEGEBAILE, 2009), indicando-nos que em nossa trajetória histórica, sempre que a política educacional é expandida de modo visível, sua qualidade é rebaixada. Nesse sentido, pensar a qualidade educacional praticada na universidade pública também é uma tarefa para quem defende a assistência estudantil, pois não bastam o acesso e a permanência, mas também é preciso formar com qualidade, base científica, pensamento crítico e humanista, articulando ensino, pesquisa e extensão.

\section{A Uerj: protoformas de assistência estudantil em experiências atuais}

No final dos anos de 1980 começa a ocorrer a ampliação do acesso à educação, como resposta ao processo de redemocratização da sociedade brasileira, das lutas de diversos movimentos sociais ${ }^{6}$, bem como das pressões de organismos internacionais pela elevação dos níveis de escolaridade da população trabalhadora (SHIROMA, MORAES; EVANGELISTA, 2000). O acesso à escola pública no Ensino Fundamental ficará evidente - entramos nos anos 1980 com 80,1\% de taxa líquida de escolarização e seguimos aos anos 2000 com 94,3\% (IBGE, 2016). No entanto, o acesso ao Ensino Médio e à Universidade acontecerá mais lentamente.

\footnotetext{
${ }^{6}$ A Ditadura Militar eliminou a exigência de gasto mínimo com educação. Além disso, a expansão das redes, principalmente a superior, foi feita a partir de instituições privadas (SAVIANI, 2008)
} 
A Uerj será uma instituição protagonista na ampliação do acesso ao Ensino Superior por meio da absorção de um corpo estudantil trabalhador. Desde o final dos anos 1970 essa universidade oferece cursos noturnos diversos - então uma excepcionalidade - permitindo que alunos-trabaIhadores ali almejem matrícula. Além disso, a localização da universidade em região servida de transportes variados, inclusive para bairros periféricos e para a região Metropolitana do Rio de Janeiro, permite o acesso de público que reside mais distante. Soma-se a esses fatos, a criação da política de cotas em 2003, revelando novamente o protagonismo uerjiano na absorção de estudantes de frações da classe trabalhadora que, historicamente, não chegavam à universidade?

Podem ser cotistas:

todos aqueles que comprovem situação de carência socioeconômica e pertençam ao grupo de alunos da rede pública de ensino; integrantes de minorias étnicas: negros (autodeclarados) e indígenas (autodeclarados); pessoas com deficiência, e filhos de policiais civis e militares, bombeiros militares e inspetores de segurança e administração penitenciária, mortos ou incapacitados por razão de serviço, nos termos da legislação em vigor. (UERJ, 2014, p. 3)

No entanto, não bastaria o acesso, somente. A chegada desses alunos e as lutas empreendidas pela comunidade universitária, especialmente por eles, desde então, concretizaram a criação de alguns mecanismos que permitiram sua permanência. Falamos de oficinas de apoio acadêmico, abertas a todos os estudantes, inclusive os não cotistas, já no primeiro ano da vigência das cotas. A seguir, falamos da bolsa para os cotistas e, mais recentemente, da criação do restaurante universitário, do acesso ao material didático, assim como da possibilidade acumular a bolsa das cotas às acadêmicas, todas essas conquistas decorrentes da luta universitária. Nesta primeira década de experiência das cotas a universidade se mostra mais democrática, mais diversa e mais popular, embora seus mecanismos de acesso e permanência possam ainda ser aperfeiçoados.

A Uerj, por meio do CAIAC (2015) nos informa que de 2003 a $201531 \%$ das vagas são de cotistas. O êxito acadêmico desses alunos - a despeito de expectativas conservadoras que marcaram a chegada desse grupo - tem sido evidenciado por estudos diversos: Amadei, (2008) e Valentim, (2012) são exemplos. A Uerj, porém, ainda prescinde de uma política de assistência estudantil estruturada de modo a acompanhar mais de perto a trajetória destes estudantes, pois contraditoriamente, apesar de ser pioneira nas cotas, está atrasada na criação de uma política de efetiva atenção aos

\footnotetext{
${ }^{7}$ Os cotistas são selecionados tendo como primeiro critério, o aspecto socioeconômico. Em 2004, na primeira experiência de seleção para as cotas, a renda per capita era de 300 reais (AMADEI, 2008). Em 2017 a per capita era de 1.320 reais,
} 


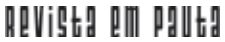

\} ASSISTENNCIA ESTUDANTIL BRASILEIRA - LESSA, S. E. C. \}

DOI 10.12957/REP.2017.30381

alunos. Sendo assim, por aqui conciliamos inovação e desproteção, protagonismo e atraso.

Visando pensar na fundamentação da política de assistência estudantil, não podemos esquecer das suas protoformas, ou seja, dos modos de atenção aos estudantes organizados antes da chegada dos cotistas. Falamos da experiência pioneira datada de 1993 e normatizada através da Ordem de Serviço OS-04/SR1/94: a Bolsa Incentivo.

Segundo Alves, Paixão e Lessa (1995) em documento da Uerj intitulado Programa de Bolsa Auxílio, a Bolsa Incentivo foi criada para estimular a permanência na universidade, em uma conjuntura de democracia, amadurecimento institucional e de realização de concursos públicos. Essa bolsa estava focada nos estudantes que obtiveram isenção da taxa de inscrição no concurso vestibular, a partir da comprovação de sua condição socioeconômica. Assim, o primeiro aluno isento de pagamento de taxa de inscrição e aprovado vestibular, ou seja, aquele que havia comprovado impossibilidade de pagar o processo seletivo, tinha acesso a uma bolsa de apoio para a permanência pelo período de dois anos, renovável por mais um, além de receber material didático do curso e de contar com um professor tutor, responsável por seu acompanhamento acadêmico pelo período de duração da bolsa.

Tratava-se, portanto, de uma iniciativa limitada, pois estava focada em apenas um estudante por curso, mas expressava o entendimento de que a Uerj precisava responder às demandas dos alunos empobrecidos. A presença deles estava ali reconhecida institucionalmente.

Neste sentido, entendemos a Bolsa Incentivo como inovação e como a primeira forma de atenção ao estudante empobrecido na Uerj; daí o seu destaque. Como exemplo desse fato, lembramos que $90 \%$ dos estudantes bolsistas possuíam uma renda familiar entre um e três salários mínimos, $60 \%$ trabalhavam e 58\% complementavam a renda familiar com a bolsa recebida (ALVES, PAIXÃO e LESSA, 1995). O professor tutor será aquele que o orientava frente à caminhada no curso, sobre as demais bolsas existentes e sobre a graduação escolhida.

Associada à Bolsa Incentivo o Departamento de Estágios e Bolsas (CETREINA) contava com uma equipe formada por assistentes sociais concursadas, psiquiatra e estagiários de Psicologia (supervisionados pela faculdade) que desenvolviam os processos seletivos dos estudantes e seu acompanhamento. Em função desses suportes e da ação multidisciplinar, entendemos que essa é uma protoforma da experiência de assistência estudantil na Uerj.

A experiência da Bolsa Incentivo foi extinta sumariamente em 1996, frente a uma nova reitoria que não valorizou a proposta. Assim, os estudantes que ingressaram no programa ali permaneceram até completarem o tempo previsto como bolsista, a equipe de trabalho que dava suporte à experiência foi desfeita. Importante observar que há um significativo lapso 
de tempo entre essa proposta inicial e a implementação das cotas. Esse dado revela que ao longo destes 8 anos a Uerj não desenvolveu atividades organizadas institucionalmente de apoio à permanência, colocando-se em lugar de atraso na formulação de políticas desse tipo.

Com a chegada dos cotistas em 2003 foi organizada uma nova estrutura de seleção para esse estudante. Por meio do Programa de Iniciação Acadêmica (Proiniciar) o estudante passa a receber apoio para sua permanência. Tal apoio se concretiza em bolsa que pode durar o tempo máximo de integralização do curso em que o aluno está matriculado, além de proporcionar acesso ao material didático, sugerido pela unidade acadêmica a que o cotista se vincula, acesso a atividades acadêmicas instrumentais, culturais e, por fim a passe livre universitário no município do Rio de Janeiro, contendo 76 viagens por mês, a serem utilizadas no máximo 04 ao dia. Considerando que o estudante da UERJ, em sua esmagadora maioria, não reside no entorno universitário, esse número de passagens é insuficiente. Além disso, o Passe Livre Universitário não pode ser utilizado nos trens, metrô, barcas, em linhas municipais fora do município do RJ ou em viagens intermunicipais, segundo o sítio do Rio Card (2016). Soma-se a isso, o fato de que o passe está sempre em "xeque", visto que os recursos destinados ao mesmo são instáveis.

Para além da questão do passe livre, vale destacar que o estudante terá sua condição de cotista reavaliada segundo calendário institucional, a cada dois anos. Complementando a atenção ao estudante, a Uerj passou a contar com um restaurante universitário aberto a todos os alunos, docentes e técnicos administrativos desde 2011, depois de intensa mobilização.

Consideramos que a construção dessa infraestrutura de apoio é resultado das lutas dos estudantes, da comunidade universitária, bem como do empenho das equipes atuantes na área para aperfeiçoamento desta experiência, especialmente, o Serviço Social. Vale reforçar nosso respeito e admiração pelas assistentes sociais que atuam na política de cotas, algumas delas desde o início dessa política.

Em nossa experiência profissional pudemos vivenciar a competência dessa equipe na organização de um processo seletivo de qualidade, evidentemente, pautado na ética, que busca o diálogo com os candidatos, apesar as limitadas condições de trabalho e da reduzida equipe. A estrutura disponibilizada para essas assistentes sociais (tamanho e recursos) não permite pensar no acompanhamento dos estudantes nos moldes de uma política de assistência estudantil que tenha como referência o PNAES, que pressupõe uma rede mais ampla de ação e o consequente aumento da equipe técnica. Sem isso, as potencialidades que a política de assistência estudantil contém, não podem ser aprofundadas. Dessa forma, entendemos que a Uerj, pioneira nas cotas, fica atrasada e possui um apoio estudantil incompleto.

Neste sentido, reforçamos a importância de que a universidade se inspire no atendimento nos moldes da PNAES, decreto 7234/2010 - de 


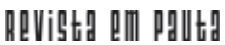

\} ASSISTÊNCIA ESTUDANTIL BRASILEIRA - LESSA, S. E. C. \}

DOI $10.12957 /$ REP.2017.30381

jurisdição federal, mas que pode servir de referência para o trabalho. Isto porque esse modelo propõe amplo escopo de ações, a saber: moradia, transporte, atenção à saúde, inclusão digital, cultura, esporte, creche, apoio pedagógico, suporte ao deficiente, transportes globais do desenvolvimento, altas habilidade e superdotação. Entendemos que o Serviço Social tem experiência nesse campo, possuindo competência profissional e ética para realização dessa proposta, juntamente com equipe multidisciplinares (psicólogos e pedagogos). Sua ação na seleção e no acompanhamento desses estudantes é plena de possibilidades que precisam ser materializadas ${ }^{8}$.

Vale, ainda, ressaltar que a universidade fluminense/carioca possui aspecto sui generis: os cotistas já ingressam na universidade nessa condição, com acesso imediato à bolsa e aos demais recursos acima destacados. Em nossa pesquisa sobre a experiência nacional das IFES na Assistência Estudantil não encontramos ação similar. Em outras palavras, nas outras instituições o estudante pode ingressar como cotista, mas somente depois de matriculado e de estar frequentando o curso, é que poderá se candidatar à condição de bolsista (e essa solicitação pode não se concretizar). Ou seja, na Uerj as cotas e a assistência estudantil estão associadas, diferentemente das demais instituições, o que para nós é um aspecto bastante positivo, construído nas lutas da universidade.

Segundo nossa experiência profissional como assistente social atuante nas cotas na área do Ensino Básico (materializada oficialmente no Rio de Janeiro, por meio da Lei Estadual, BRASIL, RJ 6434/2013), nesses espaços o Serviço Social tem sido chamado a desempenhar atividades de seleção socioeconômica. No entanto, é bandeira de luta da profissão ir além dessa análise, realizando o acompanhamento de estudantes, desenvolvendo projetos, promovendo debates acerca dos temas transversais à educação, apoiando ações junto aos deficientes, organizando Creches, ações estas elencadas na PNAES, mas não somente.

Neste sentido, a possibilidade de realizar trabalhos com as famílias, com a organização dos estudantes, nas redes de serviços do entorno escolar, com a comunidade externa, divulgando a experiência das cotas (nem sempre visíveis), além de promover o controle social da experiência, devem ser metas, apesar das dificuldades. Acreditamos que essa política abre possiblidades de trabalho novas para o assistente social, demandando reflexões diante de sua expansão, complexidade, financiamento.

\footnotetext{
${ }^{8}$ O Serviço Social tem sido propositivo frente à política de assistência estudantil. Neste sentido, vale destaque, ainda em 2010, de um marco documental importante do trabalho do Serviço Social. Trata-se de material denominado "O Serviço Social na Assistência Estudantil" elaborado por assistentes sociais das IFES da região Centro Oeste (REVISTA FONAPRACE, 2012). Neste documento constam metas de trabalho, tais como a revalorização da assistência estudantil, formação de equipes multiprofissionais para atuação na área, criação de espaços de controle social, realização de estudos socioeconômicos para análise da realidade e produção de indicadores sociais. $\mathrm{O}$ documento também destaca a importância do combate às experiências caracterizadas como "bolsa trabalho", muito comuns naquele momento. Como podemos ver, o Serviço Social tinha (e tem) contribuições importantes a dar neste processo.
} 


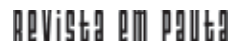

\} ASSISTÊNCIA ESTUDANTIL BRASILEIRA - LESSA, S. E. C. \}

DOI 10.12957/REP.2017.30381

Voltando aos usuários dessa política, é importante conhece-los melhor, produzir indicadores sociais sobre sua relação com a universidade, apontar êxitos e limitações dessa experiência. Para além disso, nesse momento, frente ao corte de gastos com a educação e de uma conjuntura em que o debate sobre o pagamento de mensalidades no Ensino Superior público ressurge com força, defender a educação pública, as cotas e a assistência estudantil como condição de permanência nos parece fundamental.

Por fim, queremos ressaltar que o ingresso dos filhos da classe trabalhadora nas instituições públicas de qualidade e na Educação Superior pública, em especial, bem como sua recente permanência ${ }^{9}$ é uma novidade importante, visto que é fruto da democratização da sociedade brasileira e das lutas por ampliação do acesso à educação, inclusive dos mais pobres. No movimento de estudantes a assistência estudantil é uma das bandeiras que podem colocar em xeque a dinâmica institucional, as relações entre universidade, alunos e governantes.

Neste sentido, a universidade pública não será mais aquela que acolhia, especialmente, os rebentos brancos das camadas médias urbanas. Esta tardia instituição brasileira está sendo desafiada a se reinventar. Os filhos da desigualdade e da vida precarizada estão cada vez mais em seu interior e não será possível ignorá-los. Dialeticamente, a universidade, instituição pensada para atender às elites, será pressionada para que efetive mudanças ${ }^{10}$. Neste sentido, a assistência estudantil deve ser uma política mobilizada para e pela juventude pobre, que reconhece as dificuldades na consolidação do direito à educação, em um país extremamente desigual.

Neste momento, todas essas conquistas e potencialidades estão fragilizadas, frente à crise provocada pela má gestão dos Governos Cabral e Pézão (mas não só), bem como pela prioridade que tais governos deram a não-tributação de grandes empresas que atuam no estado do RJ, ampliando o déficit público fluminense. Assim, a Uerj passa pela maior crise de sua história. A precarização da sua infraestrura física, o não pagamento de bolsas e salários e seu evidente desfinanciamento, se integra a um projeto nacional de ataque à universidade pública, em que na linha de frente, estão atualmente, as estaduais. Assim pensar em projetos de ampliação de cotas e de sua estrutura de apoio, nos parece inviável, no momento. No entanto, a Uerj resiste, reage e luta por sua existência, por sua história.

Finalizamos ressaltando que a presente reflexão militante é construída por uma assistente social atuante no campo da Educação, que trabalhou em programa de assistência estudantil e que acredita nas potencialidades contidas nesta experiência. Dessa maneira, defendemos que a

\footnotetext{
${ }^{9}$ O PNE prevê que até 2024 o Ensino Fundamental de nove anos esteja universalizado para todos os indivíduos de até 14 anos. A questão é pensarmos como isso será feito: com aprovações indiscriminadas ou com acompanhamento efetivo destes estudantes.

${ }^{10}$ Interessante destacar frase de mobilização de estudantes cotistas: "Uerj de cotas, de favelado, que quando luta, ninguém fica parado"
} 
Uerj não pode continuar no lugar contraditório de ser protagonista nas cotas, sem efetivar uma ação de assistência estudantil à altura de sua história e de seu compromisso com a educação pública. A Uerj está viva, pulsante e deve se abrir cada vez mais à condição de universidade popular, que acolhe a classe trabalhadora. Há muita luta pela frente. A assistência estudantil e as cotas são elementos fundamentais deste processo de reação e de resistência. 


\section{Referências}

ALGEBAILE , E. Escola pública e pobreza no Brasil: a ampliação para menos. Rio de Janeiro: FAPERJ/Lamparina, 2009.

ALMEIDA, N. L. T. de. Serviço Social e política educacional: um breve balanço dos avanços e desafios desta relação, 2003. Disponível em: <www. cress-mg.org.br/textos/>. Acesso em: 01 nov. 2004.

ALVES, L. de A., PAIXÃO, R. A. da, LESSA. S. E. do C. Rio de Janeiro, UERJ, Programa Bolsa Auxílio exercício 1994. Supervisão e Redação SR1, Cetreina, CODEN, 1995.

AMADEI, S. Sistema de Cotas na UERJ: uma análise quantitativa dos dados de ingresso. Revista Eletrônica do Vestibular. 1, 2008. Disponível em: <http:/ /www.revista.vestibular.uerj.br/artigo/artigo.php?seq_artigo=6>. Acesso em: 23 ago. 2016.

AMMANN, S. B. Ideologia do desenvolvimento de comunidade. São Paulo: Cortez, 1987.

ANDIFES, Gênero, renda e raça na universidade brasileira. Disponível em: <http://www.maxpressnet.com.br/Conteudo/1,860707,Genero_renda_e_ raca_na_universidade_brasileira,860707,8.htm>. Acesso em: 20 ago. 2017.

ANDRES, A. Aspectos da assistência estudantil nas universidades brasileiras. Câmara dos Deputados, Brasilia, 2011. Disponível em: <http://www2.camara .leg.br/documentos-e-pesquisa/publicacoes/estnottec/areas-da-conle/tema 11/2011_4354.pdf>. Acesso em: 02 fev. 2016.

BOSCHETTI, I. Implicações da crise do capital na política de educação superior no Brasil no contexto atual. In: SANTOS, C. M. dos; LEWGOY, A. M. B. e ABREU, M. H. E. A supervisão de estágio em Serviço Social: aprendizados, processos e desafios. RJ, Lumen Juris, 2016.

BRASIL, Constituição Federal de 1988. Disponível em: <http://www.planalto. gov.br/ccivil_03/constituicao/constituicaocompilado.htm>. Acesso em: 13 jun. 2014.

. Lei de Diretrizes e Bases da Educação Nacional. LDBN, Lei 9394/ 96. Disponível em: <http://www.planalto.gov.br/ccivil_03/leis/L9394.htm>. Acesso em: 13 jun. 2014.

. Lei Estadual/ RJ 6434/2013. Disciplina sobre o sistema de cotas para a Universidade do Estado do Rio de Janeiro, em relação ao Instituto de Aplicação Fernando Rodrigues da Silveira, CAp/UERJ. Disponível em: <http:/ /alerjln1.alerj.rj.gov.br/CONTLEI.NSF/f25571cac4a61011032564f e0052c89c/087bb8cd053320fc83257b4f0066f6f1? OpenDocument>. Acesso em: 13 jun. 2014. 


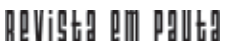

\} ASSISTÊNCIA ESTUDANTIL BRASILEIRA - LESSA, S. E. C. \}

DOI 10.12957/REP.2017.30381

BRASIL. Plano Nacional de Educação. Lei 10772. PNE, 2001. Disponível em: <http://portal.mec.gov.br/arquivos/pdf/L10172.pdf>. Acesso em 14 jun. 2017.

FERNANDES, F. O desafio educacional. São Paulo: Cortez: Autores Associados, 1989.

FRANCO, A. de P. Ensino Superior do Brasil: cenário, avanços e contradições. In: Jornal de Políticas Educacionais. 4, jul/dez, 2008. Disponível em: <http:/ /www.jpe.ufpr.br/n4_6.pdf pag 53-63>. Acesso em 02 jul. 2016.

FRIGOTTO, G. A produtividade da escola improdutiva. São Paulo: Cortez, 1993.

FUMP. Assistência Estudantil da UFMG. Histórico. Disponível em: <www. fump.ufmg.br>. Acesso em: 16 ago. 2017.

LE GOFF J. História e memória. Campinas, SP: Editora Unicamp, 1990

IBGE. PNAD 2015. Disponível em: <http://www.ibge.gov.br/home/estatistica/ pesquisas/pesquisa_resultados.php?id_pesquisa=149>. Acesso em: $13 \mathrm{abr}$. 2016.

INEP. Instituto Nacional de Estudos e Pesquisas Educacionais Anísio Teixeira. Mapa do Analfabetismo no Brasil. Disponível em: <http://www. plataformado letramento.org.br/acervo-para-aprofundar/249/mapa-do-analfabetismo-nobrasil-inep.html>. Acesso em 29 jun. 2016.

LESSA, S. E. do C. A formação via PNQ e inserção produtiva dos CRAS. A reprodução empobrecia e emergencial da qualificação de trabalhadores. Revista Serviço Social e Sociedade, 106. São Paulo: Cortez, 2011.

MANFREDI, S. M. Educação Profissional no Brasil. São Paulo, Cortez, 2003. NETTO, José Paulo. Ditadura e Serviço Social. Uma análise do Serviço Social no Brasil pós 1964. São Paulo: Cortez, 1991.

MEC. Censo Escolar 2015. Disponível em: <http://portal.inep.gov.br/basicacenso>. Acesso em: 01 mar. 2016.

. Expansão da Rede Federal de Educação profissional e Tecnológica.

Disponível em: <http://institutofederal.mec.gov.br/>. Acesso em: 01 mar. 2016.

NETTO. J. P. Ditadura e Serviço Social. Uma análise do Serviço Social no Brasil pós 1964. São Paulo: Cortez, 1991.

PASSETTI, E. Crianças Carentes e Políticas Públicas. In: PRIORE, M. D. (Org.). História das crianças no Brasil. Questões da nossa época. São Paulo: Contexto, 2000.

PINHEIRO, M. I. Serviço Social: infância e juventude desvalidas. São Paulo: Cortez, 1985. 
Revista FONAPRACE. Documentos produzidos 2001. Disponível em: <http:/ /www.unb.br/administracao/decanatos/dac/fonaprace/documentos/pna.htm >. Acesso em: 3 mar. 2016.

. Histórias, memórias e múltiplos olhares. Organização Fórum Nacional de Pró-reitores de Assuntos Comunitários e Estudantis, coordenação, ANDIFES. - UFU, PROEX: 2012.

RIO CARD. Passe Livre Universitário. Disponível em: <https://www.cartao riocard.com.br/rcc/gratuidade/passeLivre>. Acesso em 16 ago. 2016.

ROMANELLI, O. de O. História da Educação no Brasil. São Paulo: Vozes, 2001. SAMPAIO, H. O setor privado de Ensino Superior no Brasil: continuidades e transformações. Revista Ensino Superior, Unicamp, 2011. Disponível em: $<$ https://www.revistaensinosuperior.gr.unicamp.br/edicoes/ed04_outubro 2011/05_ARTIGO_PRINCIPAL.pdf>. Acesso em 24 abr. 2016.

SAVIANI. D. O legado educacional do regime militar. Cadernos Cedes, Campinas, vol. 28, n. 76, 2008.

SHIROMA, E. O., MORAES, M. C. de, EVANGElistA, O. (orgs). Política Educacional. Rio de Janeiro, DP\&A, 2000.

UERJ. CAIAC. Levantamento de cotas 2015. Disponível em: <http://www. caiac.uerj.br/documentos/LEVANTAMENTO_inicial_2015.pdf>. Acesso em: 09 ago. 2016.

UERJ. CAIAC. Relatório de atividades 2014. Disponível em: <http:// www.caiac.uerj.br/documentos/Relatorio\%20Consolidado\%20CAIAC\% 202014.pdf>. Acesso em: 09 ago. 2016.

UERJ. Manual Informativo do Aluno Cotista da UERJ. Disponível em: <http:/ /www.caiac.uerj.br/documentos/CARTA\%20AO\%20ALUNO\%202015 .pdf>. Acesso em: 02 jul. 2016.

UNB, FONAPRACE. Documentos produzidos, 2001. Disponível em: <http:/ /www.unb.br/administracao/decanatos/dac/fonaprace/documentos/pna. htm>. Acesso em: 03 mar. 2016.

VALENTIM, D. F. D. Ex-alunos negros. Os desacreditados e o sucesso acadêmico. Tese de Doutorado. Pontifícia Universidade Católica do Rio de Janeiro, 2012. Disponível em: <http://www2.dbd.puc-rio.br/pergamum/teses abertas/0811292_2012_pretextual.pdf>. Acesso em: 02 jan. 2016.

WITIUK, I, L. A trajetória sócio-histórica do Serviço Social no espaço da educação escolarizada. 2004, 331f. Tese de Doutorado. Pontifícia Universidade Católica de São Paulo. São Paulo, 2004. 
| ASSISTÊNCIA ESTUDANTIL BRASILEIRA - LESSA, S. E. C.

DOI 10.12957/REP.2017.30381

Recebido em 17 de setembro de 2016.

Aprovado para publicação em 13 de dezembro de 2016.

DOI 10.12957/rep.2017.30381

\section{(c) (1)}

A Revista Em Pauta: Teoria Social e Realidade Contemporânea está licenciada com uma Licença Creative Commons Atribuição 4.0 Internacional.

EM PAUTA, Rio de Janeiro - 1º Semestre de 2017 - n. 39, v. 15, p. 155 - 175

Revista da Faculdade de Serviço Social da Universidade do Estado do Rio de Janeiro 